\title{
Studies on Nano Cellulose Century Fiber Composites
}

\author{
C. Shashikanth ${ }^{1}$, D. K. Nageswara Rao ${ }^{2}$ \\ ${ }^{1}$ Assistant Professor, Mechanical Engineering, ${ }^{2}$ Professor \\ Malla Reddy College of Engineering, Hyderabad, Telangana, India
}

\begin{abstract}
Nano cellulose composites are used for advanced applications for structural parts and electronic components. Biocompatible water soluble cellulose composites are used in medical applications as well. Nano cellulose fibers are extracted through various chemical and mechanical treatments to separate the cellulose and to further refine it. Composites are made using thermosetting polyester resin and biodegradable poly vinyl (PVA). A research work is proposed in this paper for extraction of lignocellulose and nano cellulose fibers from century plant and developing the composites for evaluation of TGA, DSC, DMA, dielectric, tensile, flexural, impact, hardness and hygroscopic properties. Applications for the composites will be suggested based on the the properties of the composites.
\end{abstract}

Keyword: Century fiber composites; nanocellulose fibers; nano cellulose composites; biodegradable composites.

\section{INTRODUCTION}

Nano-cellulose composites have drawn the attention of the researchers for development thermosetting and biodegradable materials for automotive, packaging and medical applications [1-10]. Nano cellulose fiber composites are fully biodegradable and biocompatible with excellent mechanical properties. Due to high crystallinity and high aspect ratio and low density of the nano cellulose fibers, there is considerable increase in the stiffness of the composites produced.

\section{LITERATURE REVIEW}

The comparative study [1-3] of mechanical, thermal, electrical and water absorption properties of different natural fiber composites has identified that the Century fiber has great potential to give better properties. There has been an increasing interest on use of natural fiber composites over the last decade and extensive research has been carried out to explore the best properties for various applications [4, 5]. Nano cellulose fibers are isolated from a variety of natural fibers by chemical and mechanical treatments [5]. Chemical treatments prior to mechanical treatments reduce the size of the fibers before homogenization by [6] and reduce the energy consumption during mechanical treatments. Different chemical treatments include: alkaline treatment coupled with high pressure defibrillation, acid treatment, enzyme-assisted hydrolysis and acid hydrolysis. Mechanical treatments include: high pressure irna homogenization, ultrasonication, cryocrushing and grinding. Isolation of nano fibers is assisted by oxidation pretreatment by 2Tetramethylpiperidine-1-oxyl (TEMPO) that facilitates. Other methods include steam explosion and electro-- spinning [7-11]. Nano fibrillated cellulose (NFC) reinforced composites are produced using phenolic resin.

Styrene butyl acryl ate amyl pectin, polyurethane, melamine formaldehyde, etc. Nano composites are made by hand layup technique using bio-based epoxy resin and TEMPO oxidized NFC. The specimens are investigated for mechanical, dynamic mechanical, thermal [12] and dielectric properties as well as humidity absorption, morphology and transparency of the composites [6]. Different biodegradable polymers used are: PEO-poly (ethylene oxide), PVA-poly (vinyl alcohol), and PAA- poly (acrylic acid), PCL-poly ( $\varepsilon$-caprolactone), PLA- poly (lactic acid), PS-polystyrene, EVOH-ethylene-vinyl alcohol copolymer, PMMA-poly (methyl methacrylate) [12, 14]. Thermoplastic rice straw nano cellulose composites are made using reinforced starch polymer [15]. In the first step, almost all the non-cellulosic components are removed from the straw and a white pulp of cellulosic fibers are obtained. Then a diluted 
suspension of fibers was ultra-sonicated to destroy inter molecular hydrogen bonds and nano fiber networks are obtained. The fibers are then used for casting films of the composite. It was found that the yield strength and Young's modulus of the nano composites is due to the reinforcement by cellulose fibers. Humidity Absorption resistance significantly enhanced.

Recently, modified cellulose has been used as reinforcement for various composites with water soluble polymers. Addition of cellulose increased the viscosity and mechanical properties and accelerated the rate of biodegradation. Chemical modification of cellulose has been an important route for the production of multifunctional materials. High strength biodegradable composite films for membrane and packaging applications are developed by film casting method using modified cellulose with poly(vinyl alcohol) in different compositions $[8,15,16]$. These films are characterized for mechanical, moisture absorption, gas barrier, and biodegradable properties $[16,17]$. They have shown good transparency, flexibility, good mechanical and biodegradable properties. These films have exhibited better barrier properties with increase in percentage of modified cellulose. Literature review revealed that reported research has not been found on Century cellulose nano fiber composites. Century fibers will be extracted from Agave Americana plants are abundantly available as border plant. The century fibers are widelyused in the textile and paper industry. The century nano cellulose fibers will be used to cast various structural parts in Automobiles, electronic and packaging industry.

\section{PROPOSED WORK}

The proposed research work is to produce wealth from waste by developing useful products from desert plants. By extracting nano cellulose fibers from leaves of Century plant. Century nano cellulose fiber sheets are molded using thermoset polyester resin and also poly (vinyl alcohol), a biodegradable resin.

The composites will be tested for various mechanical properties such as: flexural, tensile, fracture, impact, Barcol hardness and water absorption and dielectric breakdown properties. Thermal properties like, glass transition temperature and thermal degradation will be studied using Differential Scanning Calorimetry and Thermogravimetric Analysis respectively. Scanning Electron Microscopy will be done to study the fracture behavior of the composite. Based on the results of the studies, the scope of application of the material will be suggested.

\section{PREPARATION OF NANO CELLULOSE COMPOSITES}

\section{A. Century Plant}

Century (Agave Americana) plant belongs to Agavaceae family and is native to Mexico and its name is derived referring to the long time it takes to flower. These plants grow in clusters and are generally used for fencing. Their leaves are $2 \mathrm{~m}$ long and $25 \mathrm{~cm}$ wide. They are located as a rosette without trunk. Century fiber has drawn attention by several researchers because of their large leaf length, leaf biomass, fiber length, fineness, density and high strength.

\section{B. Extraction of Century Fibers}

The lignocellulosic fibers from Century plant are produced from leaves by retting process. The leaves are cut and dried to allow the watery substance to evaporate and then soaked in still water for 15 days. The fermented soft greenish substance is washed thoroughly and the fibers are peeled off the leaves and are washed and dried in shady place. The length of the fibers is between $100-123 \mathrm{~cm}$ and the size ranges between $150 \mu \mathrm{m}$ to $300 \mu \mathrm{m}$.

\section{Extraction of Cellulose [16,17]}

Cellulose is extracted by a process called water prehydrolysis [10]. The fibers which are of 1-1.25 m long are cut into approximate length of $5-10 \mathrm{~mm}$. The chopped fibers are dewaxed where a mixture of Toulene/ethanol $(2: 1 \mathrm{vol} / \mathrm{vol})$ is poured in flask and the fibers were put in a cloth and placed in the Soxhlet extractor and boiled at a temperature of $70^{\circ} \mathrm{C}$ for 6 hours. They are washed with ethanol for $30 \mathrm{~min}$ and then allowed to dry. The de-waxed fibers are then mixed with $0.1 \mathrm{M} \mathrm{NaOH}$ in $50 \%$ volume of ethanol at $45^{\circ} \mathrm{C}$ for 3 hours under continuous stirring by keeping the beaker on a magnetic stirrer. Then the fibers are treated with $\mathrm{H}_{2} \mathrm{O} 2$ at $\mathrm{pH}=10.5$ (buffer solution) is carried out at $45^{\circ} \mathrm{C}$ in a solution of $\mathrm{H}_{2} \mathrm{O} 2$ with different concentrations, viz., (a) $0.5 \% \mathrm{H}_{2} \mathrm{O}_{2}$ (b) $1 \%$ $\mathrm{H}_{2} \mathrm{O}_{2}$ (c) $2 \% \mathrm{H}_{2} \mathrm{O} 2$ (d)3\% $\mathrm{H}_{2} \mathrm{O} 2$ for 3 hours each under continuous agitation. Then each mixture is treated with $10 \% \mathrm{w} / \mathrm{v} \mathrm{NaOH}+1 \% \mathrm{w} / \mathrm{v}$ $\mathrm{Na} 2 \mathrm{~B} 4 \mathrm{O} 7.10 \mathrm{H} 2 \mathrm{O}$ at $32^{\circ} \mathrm{C}$ for 15 hours under continuous stirring. Then, solid obtained will be filtered off. Salt formation will be confirmed by solubility test, since it is freely soluble in water. This 
salt will be treated with 2-(Trifluromethyl) benzoylchloride in the presence of pyridine as a base cum Solvent and stirred overnight at $100^{\circ} \mathrm{C}$.

At the end of the process, only cellulose will be left which is then washed with $95 \%$ ethanol and then water and dried at $60^{\circ} \mathrm{C}$ in an oven until the weight remains constant. Then the fibers are ground to obtain in the form of a powder. Important stages are illustrated in Fig. 1.

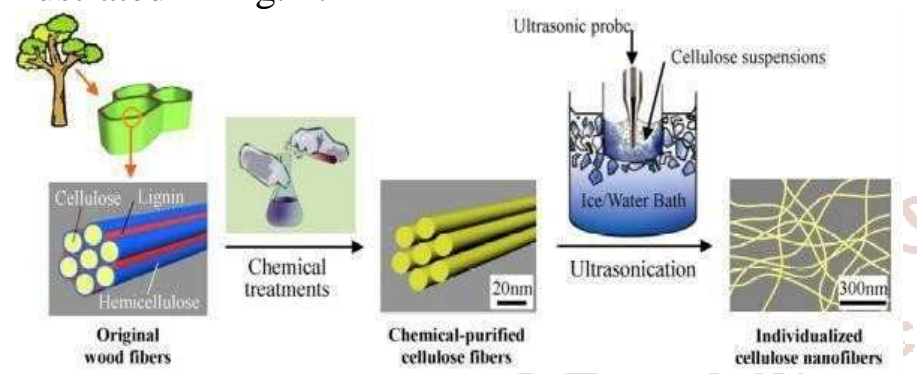

Fig.1. Different stages of extraction of nano cellulose fibers

\section{Casting of Biodegradable CompositeFilms[9]}

Modified cellulose of 2-(Trifluromethyl) benzoylchloride will be taken in water along acetonitrile as purifying solvent and Poly(vinyl alcohol) as matrix in different proportions as: $10: 90$, $20: 80,30: 70,40: 60,50: 50,60: 40,70: 30,80:$ $20,90: 10$, and $95: 05$ ratios. The reaction mixture was heated to $100^{\circ} \mathrm{C}$ for $24 \mathrm{hrs}$. After $24 \mathrm{hrs}$, the reaction mass will turn to viscous state, it will be allowed to reach room temperature and spread on the Teflon mold of one square feet with $3 \mathrm{~mm}$ depth. The mold will be coated with mold releasing spray and dried under vacuum oven at $100^{\circ} \mathrm{C}$ to remove water contents completely. After complete drying of the cast films, they are stored in moisture free environment.

\section{EVALUATION OF PROPERTIES}

\section{A. Preparation of Specimens and Testing}

Preparation of specimens for flexural test tensile test Impact test hardness, moisture absorption test will be done as per corresponding ASTM standards. For morphology studies, Scanning Electron Microscope (SEM) was used.

\section{B. Flexural test, flexural strength, flexural modulus}

The flexural strength $\left(\mathrm{N} / \mathrm{m}^{2}\right)$ of a material is defined as the ability to resist deformation under transverse loads. Flexural properties will be evaluated as per ASTM D-790-03 through three-point bend test on compression testing machine supplied by Hydraulic and Engineering Instruments, New Delhi, at a cross head speed of $1.25 \mathrm{~mm} / \mathrm{minute}$, at standard laboratory atmosphere of $23^{\circ} \mathrm{C} \pm 2{ }^{\circ} \mathrm{C}\left(73.4^{\circ} \mathrm{F} \pm 3.6^{\circ} \mathrm{F}\right)$ and $50 \pm$ 5 percent relative humidity. Specimens for flexural test are cut from laminas as per ASTM D790.

Flexural Strength: Flexural strength is the maximum stress in the outer surface of the specimen at the moment of break. When the homogeneous elastic material is tested with three- point system, the maximum stress occurs at the midpoint.

Flexural Modulus: Flexural modulus $\left(\mathrm{N} / \mathrm{m}^{2}\right)$ is the ratio of flexural stress to the strain in flexural deformation.It is a measure of the stiffness during the initial part of the bending process. Flexural modulus is the ratio of stress to corresponding strain within the elastic limit.

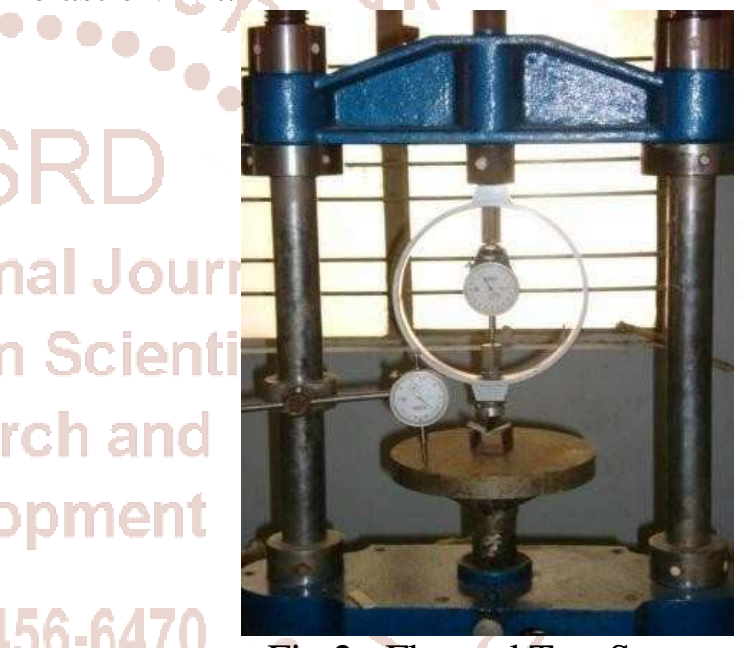

Fig.2. Flexural Test Setup

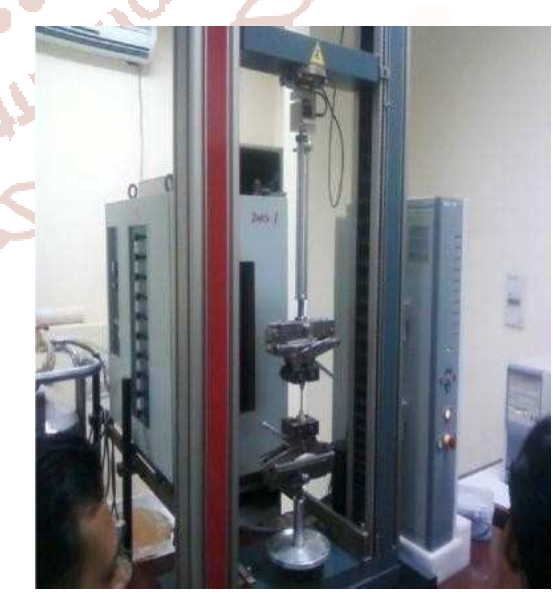

Fig.3. Universal Testing Machine Zwick/Roell Z010

\section{Tensile test, tensile strength and tensile modulus}

Tensile Strength: It is the maximum stress $\left(\mathrm{N} / \mathrm{m}^{2}\right)$ that the material can withstand before failure. It is also called as ultimate tensile strength. 
Tensile Modulus: It is also known as Young's modulus $\left(\mathrm{N} / \mathrm{m}^{2}\right)$ or modulus of elasticity and is a measure of the stiffness of the material. It is given by the ratio of the uniaxial stress to the uniaxial strain.

Tensile test will be conducted on an electronic tensile testing machine Zwick/Roell Z010-10KN-UTM at a cross head speed of $3 \mathrm{~mm} / \mathrm{min}$ and gauge length of 50 $\mathrm{mm}$. Standard Type IV dumb bell shaped specimens are used as per ASTM D-638-03. The values of tensile strength and tensile modulus are obtained from the load-deflection values by taking the maximum load resisted by the specimen up to the point of fracture and the corresponding strain. Loading of the specimen on the Tensile Testing Machine and the grips used for holding the specimen are shown in Figs. 3.

\section{Impact strength}

It is the ability of the material to withstand shock loading. It is measured by the work done $\left(\mathrm{kJ} / \mathrm{m}^{2}\right)$ in fracturing the material under shock loading. Izod impact test is used in the present case. Notched impact performance of the composite is evaluated as per ASTM D-256-05 using Pendulum impact tester, model IT 30 Izod impact supplied by PSI Sales Pvt. Ltd., New Delhi, shown in Fig. 4. The size of the samples is $12 \mathrm{~mm} \mathrm{X} 60 \mathrm{~mm}$. The test specimen is supported by a vertical cantilever beam and the specimen was broken by the swing of the pendulum. The energy absorbed in doing so is measured as difference between the height of drop before rupture and the height of rise after rupture of the test specimen.

\section{E. Barcol Hardness}

Barcol hardness test characterizes the indentation hardness of the materials through the depth of penetration of an indenter, often used for composite materials. Standard test method ASTM D-2583-75 is used to find indentation hardness of the composite through Barcol impresser model no. 934-1 shown in Fig. 5.

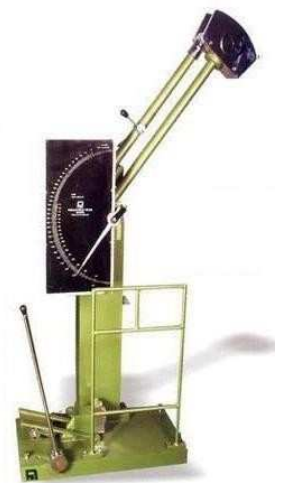

Fig.4. Pendulum Impact Tester

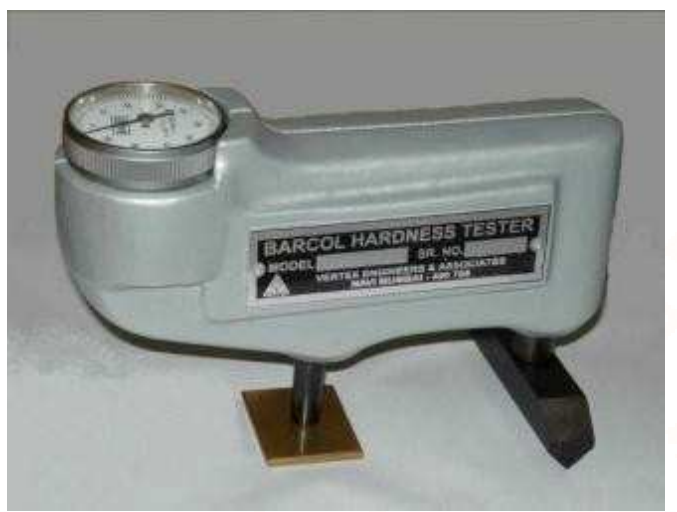

Fig.5. Barcol Hardness Tester

\section{F. Scanning Electron Microscopy(SEM)}

The morphology of fractured surfaces of the composites will be studied by Scanning Electron Microscopy (SEM) using EVOMA15 Smart SEM shown in Fig. 6. The fracture behavior of the material indicates the amount of energy absorbed before fracture, which is a measure of toughness of the material. The SEM reveals the nature of the bond between the fibers and the matrix.

Before performing SEM, The fractured specimens will be placed on a stub as shown in Fig. 7 coated with platinum and inserted into the scanning barrel. The inter-condition of the scanning barrel is vacuumed to prevent interference of scanning picture due to the presence of air. Magnification, focus, contrasts and brightness of the result is adjusted to produce the best micrographs.

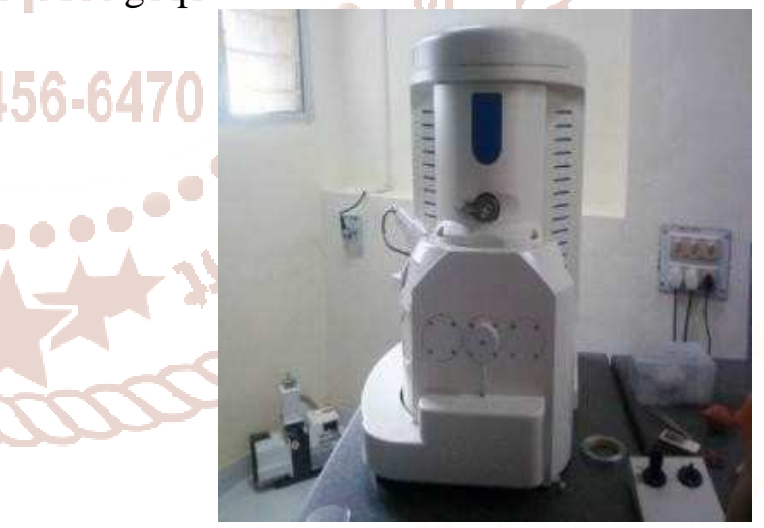

Fig.6. EVOMA15 Smart SEM

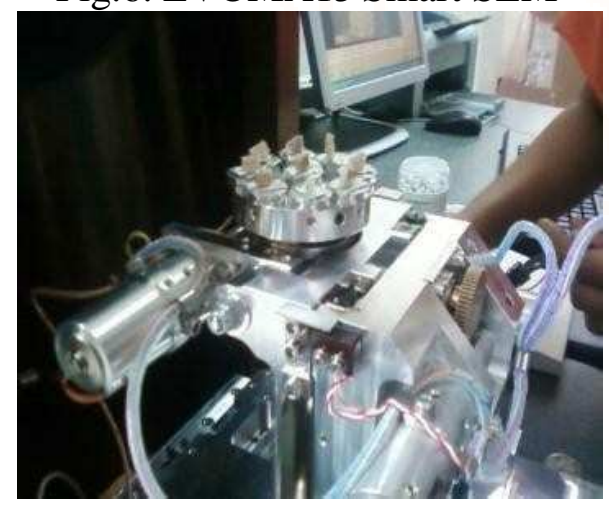

Fig.7. Stub of the EVOMA15 Smart SEM 
G. Differential Scanning Calorimetry(DSC)

Glass transition temperature $T g$ of a non-crystalline material is the critical temperature at which the material changes its behavior from hard and brittle to rubbery state. This is less than the melting temperature $\left(T_{m}\right)$. Differential Scanning Calorimetry is used for finding the $T g$ of the composites. DSC is performed with the help of Mettler using Star SW 8.1 analyzer to measure $T g$. The temperature is programmed in the range of $25^{\circ}-300^{\circ} \mathrm{C}$ with a heating rate of $10^{\circ} \mathrm{C} / \mathrm{min}$ in nitrogen atmosphere with a flow rate of $30 \mathrm{ml} / \mathrm{min}$. The Mettler DSC instrument and the silver pan used for conducting the test are shown in Figs. 9.
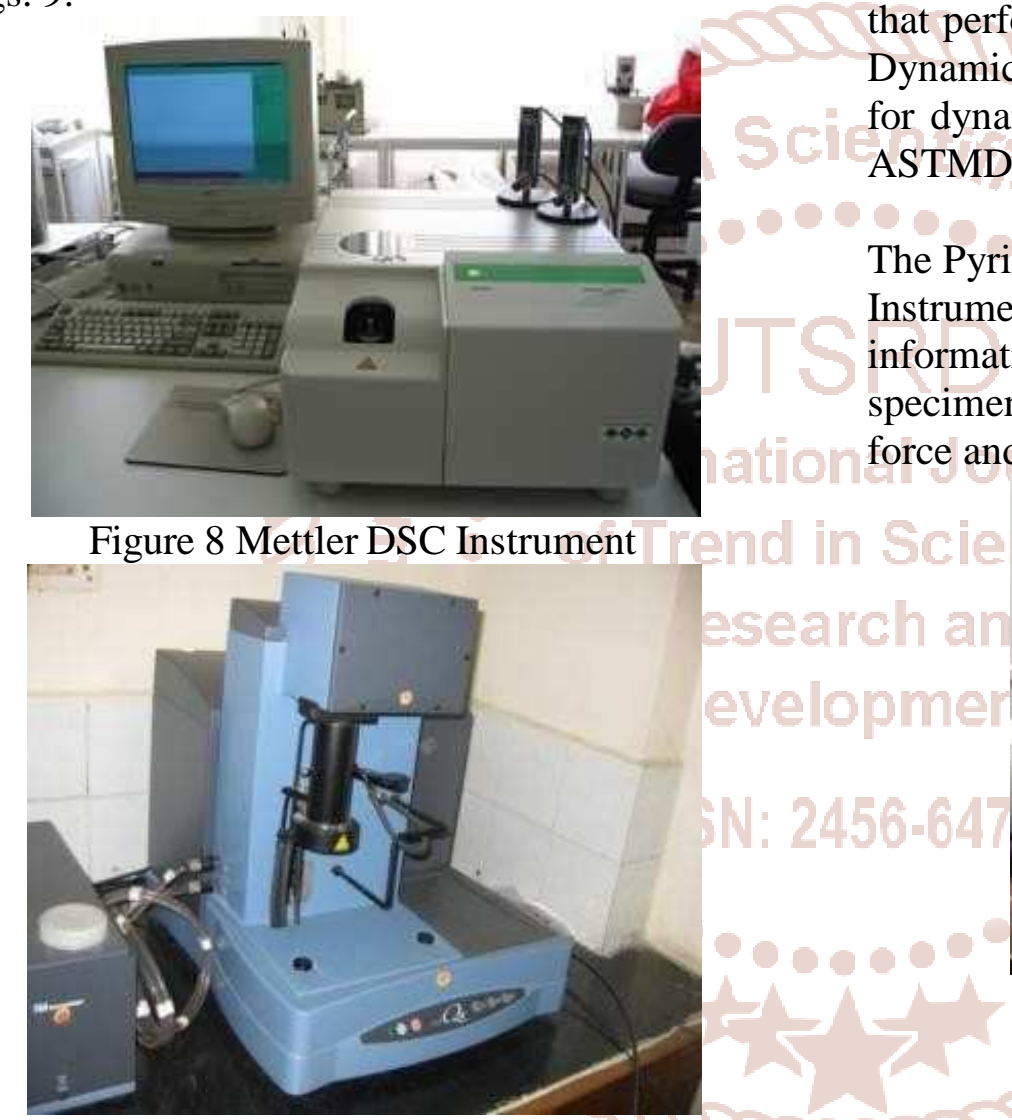

Fig.9. Thermo gravimetric Analyzer Perkin-Elmer

\section{H. Thermo gravimetric Analysis (TGA)}

Thermal degradation or weight loss due to heating is a measure of the thermal stability of the material under high temperature. Thermo gravimetric analysis (TGA) curves are used to determine the thermal degradation and thermal stability of the polymeric material. Thermal decomposition is observed as per ASTM E 1131 in terms of loss of global mass using TA Instrument TGAQ50 V20.10 Build 36 thermo gravimetric analyzer shown in Fig.9. The sample area is enclosed by a cylinder inside of the quartz tube. This energy-absorbing cylinder absorbs radiation from the lamps and heats the sample, pan, and thermocouple. Temperature is measured and controlled by a thermocouple assembly under the sample pan.

\section{Dynamic Mechanical Analysis(DMA)}

This analysis gives the storage modulus, loss modulus and damping property of the materials. Material's response for stress, temperature and frequency is determined through this test. Dynamic Mechanical Analysis, otherwise known as DMA, is a technique where a small deformation is applied to a sample in a cyclic manner. This allows the materials response to stress, temperature, frequency and other values to be studied. The term is also used to refer to the analyzer that performs the test. DMA is also called DMTA for Dynamic Mechanical Thermal Analysis. Specimens for dynamic mechanical analysis are prepared as per ASTMD 4065.

The Pyris Diamond DMA equipment by Perkin-Elmer Instruments is shown in Fig. 10. DMA yields information about the mechanical properties of a specimen placed under minor sinusoidal oscillating force and temperature.

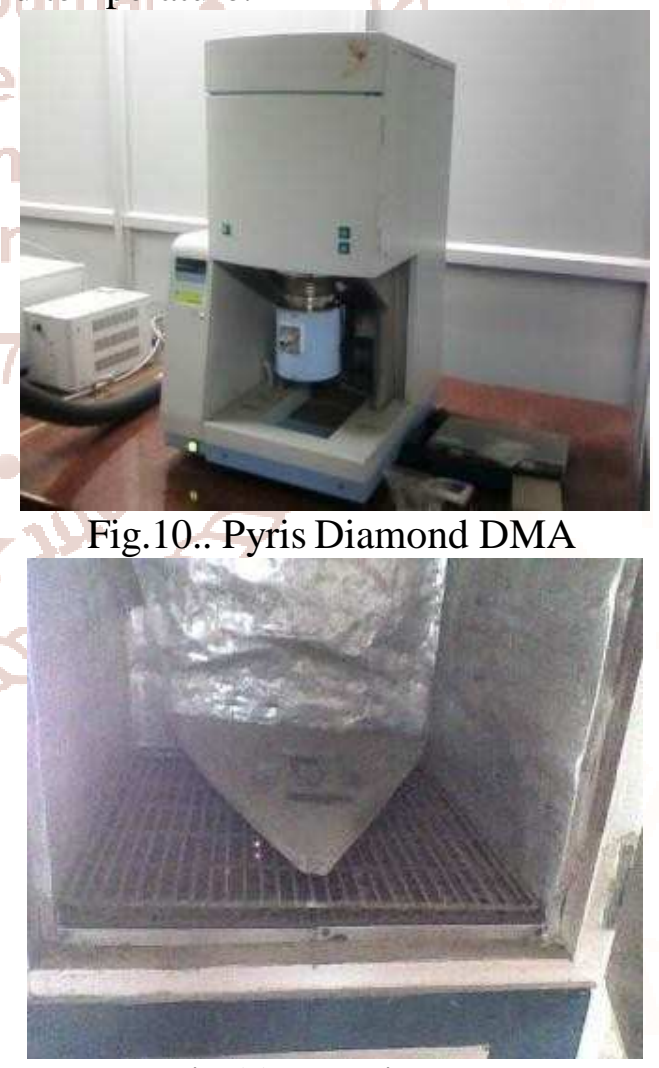

Fig.11. Hot air oven

\section{J. Dielectric Strength}

It is a measure of the electrical resistance of the material given by the maximum voltage that an insulating material can withstand before it 
decomposes or becomes a conducting material by losing its insulation property. The test is conducted as per ASTM D149: Standard Test Method for Dielectric Breakdown Voltage and Dielectric Strength of Solid Electrical Insulating Materials at Commercial Power Frequencies. Voltage at a commercial power frequency 60 hertz is applied to a test specimen. The voltage is increased from zero, until the dielectric failure of the test specimen occurs. Hipotronics 715-1A AC Dielectric Test set up will be used.

\section{K. Water Absorption}

Moisture absorption, soluble matter lost and long term immersion properties are evaluated. Water absorption tests are conducted on rectangular specimens of $76.2 \mathrm{x}$ $25.4 \mathrm{~mm}^{2}$ size shown in Fig. 18 as per ASTM D-57098. This test method covers the determination of the relative rate of absorption of water by fiber when immersed. The moisture content of a fiber is very intimately related to such properties as electrical insulation resistance, dielectric losses, mechanical strength, appearance, and dimensions.

Short Time Immersion: The samples are conditioned by heating in an oven at $50 \pm 3{ }^{\circ} \mathrm{C}$ for 24 hours and then cooling to room temperature. The weights of the samples will be taken by Shimadzu Electronic Balance (AY 220) that has a readability of $0.001 \mathrm{~g}$. All the samples are immersed in double distilled water for $24 \mathrm{hrs}$ at room temperature. Reconditioning is done by keeping them once again in the oven (Fig.11) for $24 \mathrm{hrs}$ at $50 \pm 3^{\circ} \mathrm{C}$. Percentage increase in weight of the specimen during immersion is obtained by the ratio of increase in average weight of the conditioned specimen after immersion in water for $24 \mathrm{hrs}$ and the average weight of reconditioned specimen is calculated nearest to $0.01 \%$. The amount of soluble matter lost is given by the decrease in weight of the specimen after reconditioning. The percentage of water absorbed is the sum of the \% increase in weight and the soluble matter lost.

Long Term Immersion: The total water absorbed by the conditioned specimens upon immersion for about 1200. The average $\%$ increase in weight of the specimen is calculated. The percentage increase in thickness or length or width swelling is obtained by the ratio of the increase in the respective dimension and the initial dimension.

\section{CONCLUSION}

The proposed research work on development of Century nano cellulose polyester and PVA composites can be of great value as new structural materials for automobiles, electronic devices, and packaging materials. The biodegradable PVA composites will find applications as biocompatible materials. Development of composites from these fibers will contribute for the development of Green Technology. Extraction of nano cellulose fibers from the plant fibers can grow as a cottage industry.

\section{REFERENCES}

1. K. Raja Narender Reddy, Development and Characterization of Woven Natural Fiber Composites-A Comparative Study, Ph.D. Thesis, Kakatiya University, Warangal, 2012.

2. K. Raja Narender Reddy, D.K.N.Rao, K. Gopala Kishan Rao and Kamal Kar, Studies on Woven Century Fiber Polyester Composites, Journal of Composite Materials,46(23)2012,pp.2919-2933. DOI: jcm.sagepub.com.

3. K. Raja Narender Reddy, D.K.Nageswara Rao, K. Kishore Kumar, Evaluation of Viscoelastic Properties of some Malvaceae Fiber Reinforced Composites, International Journal of Applied Engineering Research, ISSN 0973-4562, vol. 7(11), 2012, pp.1409-1413, Scopus Indexed.

4. Omar Faruk, Andrzej K. Bledzkia, Hans-Peter Fink, Mohini Sain, Biocomposites reinforced with natural fibers: 2000-2010, Progress in Polymer Science, 37: 2012; pp.1552-1596.

5. Cintil Jose Chirayil, Lovely Mathew and SabuThomas, Review of Recent Research in Nano Cellulose Preparation from Different Lignocellulosic Fibers, Rev. Adv. Mater. Sci. 37 (2014) 20-28.

6. Vijay Kumar Thakur, Manju Kumari Thakur, Processing and characterization of natural cellulose fibers/thermoset polymer composites, Carbohydrate Polymers, 2014,109 102-117.

7. Ali Abdulkhani, Jaber Hosseinzadeh, Alireza Ashori, Saeed Dadashi, Zahra Takzare, Preparation and characterization of modified cellulose nanofibers reinforced polylactic acid nanocomposite, Polymer Testing, 35:2014; pp.7379. 
8. Byung-Dae Park, In Chul Um, Sun-Young Lee, Alain Dufresne, Preparation and Characterization of Cellulose Nanofibril/Polyvinyl Alcohol Composite Nanofibers by Electrospinning, J. Korean Wood Sci. Technol., 2014, 42(2): 119 129.

9. B.Nasri-Nasrabadi,T. Behzad, and R. Bagheri, Preparation and Characterization of Cellulose Nanofiber Reinforced, Thermoplastic Starch Composites, Fibers and Polymers, 15(2):2014;pp.347-354, DOI: 10.1007/s12221014-0347-0

10. R. Masoodi, R.F. El-Hajjar, K.M. Pillai, R. Sabo, Mechanical characterization of cellulose nanofiber and bio-based epoxy composite, Materials and Design, 36:2012; pp.570-576.

11. H.P.S. Abdul Khalil, Y. Davoudpour, Md. Nazrul Islam, Asniza Mustapha, K. Sudesh, Rudi Dungani, M. Jawaid, Production and modification of nanofibrillated cellulose using various mechanical processes: A review, Carbohydrate Polymers,2014,99, 649- 665.

12. Denis Mihaela Panaitescu, Adriana NicoletaFrone, Marius Ghiurea, CatalinllieSpataru, ConstantinRadovici and Michaela DoinaIorga. Properties of Polymer Composites with Cellulose Microfibrils, Advances in Composite Materials Ecodesign and Analysis, Dr. Brahim Attaf (Ed.), 2011, ISBN: 978-953-307-150-3, InTech. Chapter 6.
13. Robert J. Moon, Ashlie Martini, John Nairn, John Simonsenf and Jeff Youngblood, Cellulose nano materials review: structure, properties and nano composites, Chem. Soc. Rev., 2011,40, 39413994.

14. Chengjun Zhou and Qinglin Wu, Recent Development in Applications of Cellulose Nanocrystals for Advanced Polymer-Based Nanocomposites by Novel Fabrication Strategies, Chapter 6, 2012, http://dx.doi.org/10.5772/46512.

15. B. Nasri,-Nasrabadi, T. Bhzad, and R. Bagheri, Preparation and Characterization of Cellulose nanofiber reinforced Thermoplastic Starch composites, Fibers and Polymers, 2014, vol. 15, No.2,347-354.

16. Sandeep S. Laxmeshwar, D.J. Madhu Kumar, S. Viveka and G.K. Nagaraja, Preparation and Properties of Biodegradable Film Composites using Modified Cellulose Fibre-Reinforced with PVA, International Scholarly Research Network, ISRN Polymer Science, Volume 2012, Article ID 154314, 8pages, doi:10.5402/2012/15431.

17. B. Goutham, Ch. Karunakar, A. Prashanth, T. Vamshi, Development and Evaluation of Some of the Mechanical Properties of Kenaf/Polyester Cellulose Composites, International Journal of Mechanical Engineering and Technology, September 2014, Volume 5, Issue 9, pp. 266-272. 